\title{
The Effectiveness of Information Technology-Supported Shared Care for Patients With Chronic Disease: A Systematic Review
}

\author{
Laura Kooij ${ }^{1}$, MSc; Wim G Groen ${ }^{1}$, PhD; Wim H van Harten ${ }^{1,2,3}$, MD, PhD \\ ${ }^{1}$ The Netherlands Cancer Institute, Division of Psychosocial Research and Epidemiology, Amsterdam, Netherlands \\ ${ }^{2}$ University of Twente, Department of Health Technology and Services Research, Enschede, Netherlands \\ ${ }^{3}$ Rijnstate hospital, Arnhem, Netherlands
}

\section{Corresponding Author:}

Wim $\mathrm{H}$ van Harten, MD, PhD

The Netherlands Cancer Institute

Division of Psychosocial Research and Epidemiology

Plesmanlaan 121

Amsterdam, 1066CX

Netherlands

Phone: 318800575

Fax: 315122322

Email: w.v.harten@nki.nl

\begin{abstract}
Background: In patients with chronic disease, many health care professionals are involved during treatment and follow-up. This leads to fragmentation that in turn may lead to suboptimal care. Shared care is a means to improve the integration of care delivered by various providers, specifically primary care physicians (PCPs) and specialty care professionals, for patients with chronic disease. The use of information technology (IT) in this field seems promising.

Objective: Our aim was to systematically review the literature regarding the effectiveness of IT-supported shared care interventions in chronic disease in terms of provider or professional, process, health or clinical and financial outcomes. Additionally, our aim was to provide an inventory of the IT applications' characteristics that support such interventions.

Methods: PubMed, Scopus, and EMBASE were searched from 2006 to 2015 to identify relevant studies using search terms related to shared care, chronic disease, and IT. Eligible studies were in the English language, and the randomized controlled trials (RCTs), controlled trials, or single group pre-post studies used reported on the effects of IT-supported shared care in patients with chronic disease and cancer. The interventions had to involve providers from both primary and specialty health care. Intervention and IT characteristics and effectiveness - in terms of provider or professional (proximal), process (intermediate), health or clinical and financial (distal) outcomes_-were extracted. Risk of bias of (cluster) RCTs was assessed using the Cochrane tool.

Results: The initial search yielded 4167 results. Thirteen publications were used, including 11 (cluster) RCTs, a controlled trial, and a pre-post feasibility study. Four main categories of IT applications were identified: (1) electronic decision support tools, (2) electronic platform with a call-center, (3) electronic health records, and (4) electronic communication applications. Positive effects were found for decision support-based interventions on financial and health outcomes, such as physical activity. Electronic health record use improved PCP visits and reduced rehospitalization. Electronic platform use resulted in fewer readmissions and better clinical outcomes - for example, in terms of body mass index (BMI) and dyspnea. The use of electronic communication applications using text-based information transfer between professionals had a positive effect on the number of PCPs contacting hospitals, PCPs' satisfaction, and confidence.

Conclusions: IT-supported shared care can improve proximal outcomes, such as confidence and satisfaction of PCPs, especially in using electronic communication applications. Positive effects on intermediate and distal outcomes were also reported but were mixed. Surprisingly, few studies were found that substantiated these anticipated benefits. Studies showed a large heterogeneity in the included populations, outcome measures, and IT applications used. Therefore, a firm conclusion cannot be drawn. As IT applications are developed and implemented rapidly, evidence is needed to test the specific added value of IT in shared care interventions. This is expected to require innovative research methods.
\end{abstract}

(J Med Internet Res 2017;19(6):e221) doi: 10.2196/jmir.7405 


\section{KEYWORDS}

review; integrated healthcare systems; health information systems; chronic disease

\section{Introduction}

In Europe, $77 \%$ of the disease burden is attributable to chronic diseases. For example, 60 million people live with diabetes [1] and $4-10 \%$ suffer from chronic obstructive pulmonary disease (COPD) [2]. Cancer is the leading cause of death in Europe with at least 3 million new cases each year, and cancer survivors are increasingly considered as having a chronic disease [3]. Many health care professionals and various providers are involved during treatment and follow-up of patients with these chronic diseases $[3,4]$. This inevitably increases fragmentation and can lead to suboptimal care [3]. Coordination of care between multiple professionals caring for patients with chronic disease is essential to guarantee quality of care $[4,5]$. However, coordination and integration of different professionals is often lacking $[3,4]$. Shared care is a means to improve integration and is defined as "the joint participation of GPs and hospital consultants in the planned delivery of care for patients with a chronic condition, informed by an enhanced information exchange over and above routine discharge and referral letters" [6]. Shared care can improve care delivery, since it involves a collaboration between primary and specialty care professionals, and this delivery of care is expected to be better than the separation of specialty and primary care [7]. Optimal information exchange between health care professionals is very important for the coordination and continuity of care $[8,9]$. However, oftentimes information exchange between professionals caring for the same patient is suboptimal $[9,10]$, since professionals lack information [9] or the information is not exchanged on time [10].

The use of information technology (IT) seems promising [10] and is increasingly used to support information exchange [6]. IT can improve information accessibility [4,11-13] and can have a positive effect on safety $[14,15]$. Additionally, IT can support health care processes and has the potential to improve quality [16] and efficiency of care processes $[15,16]$. For example, electronic referral can improve the quality of care, access to a professional, and decrease costs [17], and electronic reminders can improve efficiency [4].

An overview of the characteristics and effectiveness of IT-supported shared care interventions is lacking. Previous systematic reviews, such as by Smith et al, provided a total overview of shared care interventions for chronic disease including IT support. They found shared care to be a promising approach but only three IT-supported shared care interventions were reported on. Therefore, there is a need for more evidence, especially as the selected studies were of low methodological quality $[7,18]$. We presume that since previous reviews $[7,18]$, considerably more IT-supported shared care interventions have been developed and reported on in the literature. Also, IT applications in health care are being developed and implemented at a rapid pace and involve considerable costs. Therefore, we aim to systematically review the state-of-the-art regarding the effectiveness of IT-supported shared care interventions on the care of patients with chronic diseases: diabetes, chronic obstructive pulmonary disease (COPD), (congestive) heart failure, cardiovascular disease (CVD), hypertension, asthma, or cancer. More specifically, we aim to provide an inventory of the effects of shared care, supported by IT, on the care of patients with chronic diseases and to describe the characteristics of the IT applications that support such interventions.

\section{Methods}

\section{Information Sources and Search Strategy}

Studies were identified by searching the literature in EMBASE, Scopus, and PubMed from January 2006 to September 2015. The search consisted of three concepts: (1) shared care, (2) chronic disease, and (3) IT. Several mesh terms were used for these concepts. The full search string is provided in Multimedia Appendix 1. We also checked the reference lists of included articles to detect other relevant studies focusing on (other) chronic diseases ("snowballing method"). As we wanted to provide a total overview of IT-supported shared care interventions, we selected relevant studies from before 2006 from 2 excellent previous reviews (that searched up until 2006) $[7,18]$.

\section{Eligibility Criteria}

For the selection, we used the following eligibility criteria: (1) English-language studies describing a randomized controlled trial (RCT), nonrandomized controlled study or a single-group before and after study; (2) included a shared care intervention; (3) supported by IT; (4) developed specifically for people with a chronic disease: diabetes, COPD, congestive heart failure, CVD, hypertension, or asthma, or cancer; (5) involved health care providers were both primary care physicians (PCPs) operating outside hospitals or physician practices and specialty health care professionals; and (6) study included outcome measures focusing on at least health or clinical, process, provider or professional and financial outcomes.

\section{Study Selection}

The first and second authors independently assessed titles and abstracts focusing on the concepts of shared care, type of disease, and study type. IT was not a criterion for the abstract rejection because it was assumed that IT might only be described in the full texts. In the case of ambiguity or when there was no consensus about the abstracts, the full publication was reviewed by the 2 authors. Disagreement was resolved by discussion; when an issue remained unresolved, the decision of a third reviewer $(\mathrm{WvH})$ was decisive. This selection process was similar for the further selection of full texts.

\section{Data Extraction}

From the selected studies, we report on study characteristics (year, design, measurement time points, and country), patient population (number and type of disease), intervention characteristics (content), IT characteristics (type of application), outcome measures, and effects. The latter were structured according to provider or professional (proximal), process 
(intermediate), health or clinical and financial (distal) outcomes. These data items were extracted independently by 2 researchers (LK and WG) and disagreement was resolved by discussion.

\section{Risk of Bias Assessment}

We assessed the risk of bias of the included (cluster) RCTs by using the Cochrane risk of bias tool.

The risk of bias was independently assessed by 2 researchers (LK and WG). Disagreement was solved by discussion until consensus was reached. Each aspect and the overall risk of bias of the Cochrane risk of bias tool was graded as high, low, or unclear according to the criteria in the Cochrane handbook [19].

\section{Synthesis of Results}

For the reporting of this systematic review, we used the PRISMA guidelines [20]. Results were synthesized in a qualitative way as there were large differences in the types of intervention, target populations, and outcome measures. Due to the diversity of intervention characteristics and outcomes measures, we could not conduct a meta-analysis.

\section{Results}

\section{Study Selection}

The primary search yielded 4167 results. After title and abstract selection and the removal of duplicates, 29 papers were read in full text. Nine articles met our inclusion criteria. One additional study was found by reviewing the reference lists, and we identified 3 additional studies from the previous systematic review of Smith et al $[7,18]$. Reasons for excluding studies were inappropriate study design, no available full text, lack of a shared care intervention, and/or lack of IT support. Figure 1 gives a detailed overview of the study selection procedure.

\section{Study Characteristics}

In total, we included 8 RCTs, 3 cluster RCTs, 1 controlled trial, and 1 pre-post feasibility study. The 13 manuscripts described 11 unique studies. Two papers by Casas et al [21] and Garcia-Aymerich et al [22] described the same intervention but with different patient populations and outcome measures. Lalonde et al [23] and Santschi et al [24] both described the same intervention but assessing different outcome measures.

The included studies were conducted in Canada $(n=2)[23,24]$, Italy $(n=2)$ [25,26], Scotland $(n=3)$ [27-29], United States $(n=2)$ [30,31], Australia $(n=1)$ [32], Denmark $(n=1)$ [33], Spain $(n=1)$ [22], and Spain and Belgium $(n=1)$ [21]. The intervention groups were mostly compared with a group receiving usual care [21-25,27,29,30,32,33], with a specialist outpatient and a nurse practitioner clinic [28] or in one case through general correspondence by email [31]. 
Figure 1. Flowchart of the search and selection procedure.

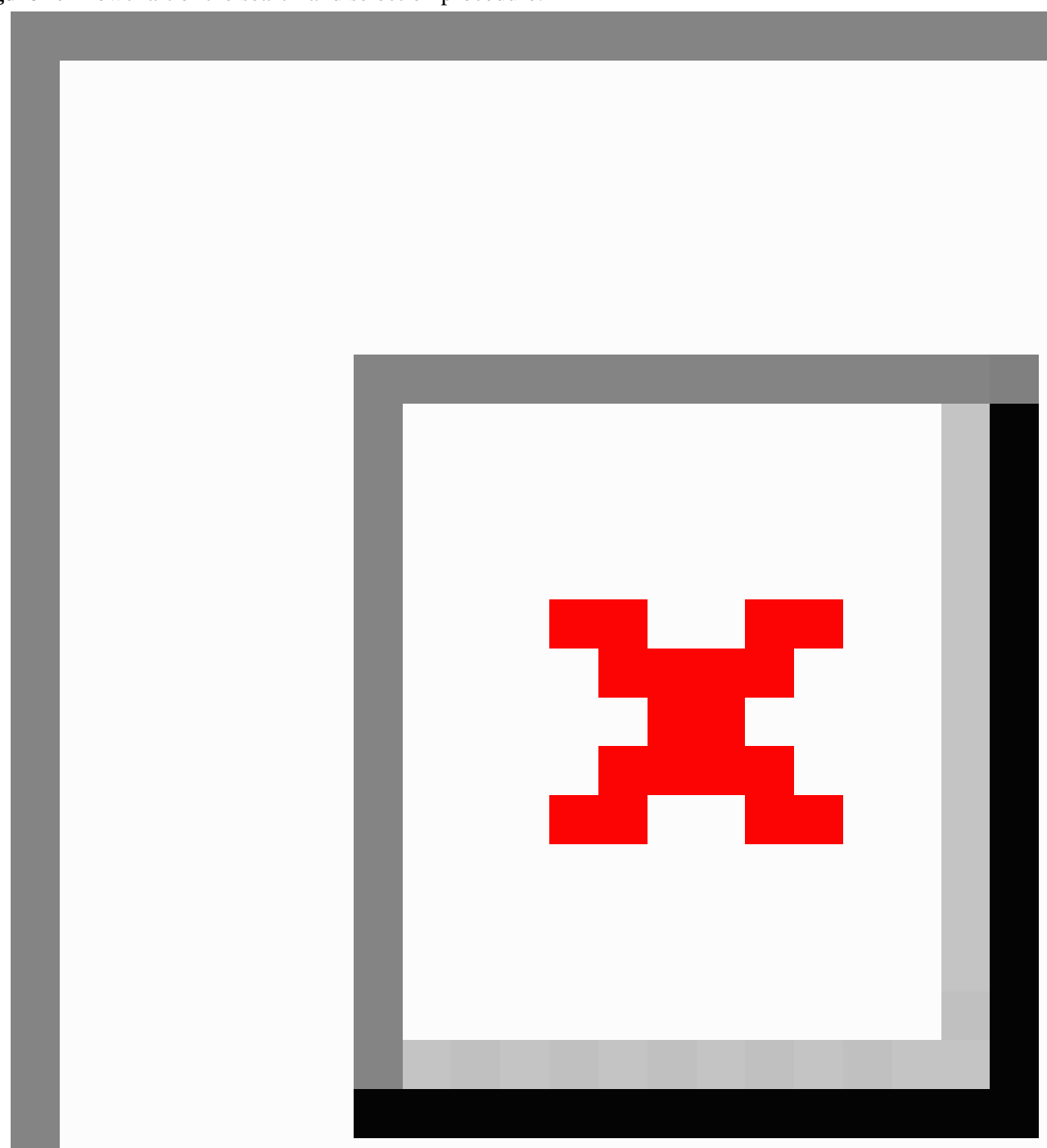

\section{Patient Population Characteristics}

Patient populations included patients with COPD $(n=2)[21,22]$; chronic kidney disease (CKD; $n=2)[23,24]$; diabetes $(n=3)$ [25,27,31]; hypertension $(n=1)$ [28]; asthma $(n=1)$ [29]; and multiple conditions, such as heart failure, diabetes, (risk for) CVD $(n=1)$ [26], and cancer $(n=2)$ [32,33]. One study did not specify the target population but considered hospital discharges in general, which included all conditions [30].

\section{Intervention Characteristics}

The intervention characteristics are presented in Multimedia Appendix 2. There was a large variation in the nature of the interventions, IT applications, and the professionals involved. The primary health care providers who participated in the interventions were PCPs or general practitioners (GPs) $(n=11)$ [21,22,25-33] and pharmacists [23,24]. Specialty care professionals included case managers $[21,22,26]$ and specialists $[23,24,28,29,31,33]$. However, in 4 interventions the type of specialty care professional was not specified $[25,27,30,32]$.

The objectives varied among the included studies. The majority of the interventions aimed to assess the effectiveness of shared care interventions on the level of distal and/or intermediate outcomes. This included (clinical) patient outcomes $[22,24,25,31]$, sometimes in combination with social and economic settings [27,29]. Other objectives were to study the effects on the number of readmissions, GP contacts with the hospital [21,30], or (diabetes) care outcomes [31]. The impact of a pharmaceutical training and communication network on 
both distal (pharmaceutical opinions and refusals, clinical outcomes) and proximal outcomes (knowledge and satisfaction of pharmacists) were assessed [24]. Proximal outcomes were also assessed, including tailored information provision to GPs [32] and hospital-based case management [33]. One study aimed to evaluate the feasibility, acceptability, and cost-effectiveness of shared care in comparison with other follow-up approaches [28].

\section{Information Technology (IT) Characteristics}

Four types of IT applications can be distinguished: electronic decision support [26,31], electronic health records (EHRs) [25,27-30], an IT platform combined with a call center [21,22], and electronic communication applications [23,24,32,33]. These will be described in more detail in the next section.

\section{Electronic Decision Support}

The electronic decision support tools were mainly used for care management, specifically for patients with diabetes [31] and (at risk of) CVD, diabetes, or heart failure [26]. A diabetes electronic management system was used to provide PCPs with decision support aimed at reducing cardiovascular risk in diabetes. PCPs received patient-specific and evidence-based information from endocrinologists via secure-email. Based on this information, PCP and patient discussed how to further continue treatment [31]. Decision support was also used to improve care coordination for patients with diabetes, heart failure, and (at risk of) CVD. Therefore, their care managers were provided with notifications and monitoring instruments [26].

\section{Electronic Health Records}

In one nonrandomized controlled study, PCPs and hospital professionals exchanged information via a connected EHR in care for diabetes patients [25]. In a RCT, a connected EHR provided GPs with information regarding their elderly patients' hospital discharge [30]. In 3 cases, the EHRs were "synchronized" and therefore used to store information, which was shared between professionals without technology involved (ie, hardcopies were sent via surface mail). GPs send information to secondary care providers, who add this to their EHR. Consequently GPs periodically receive back the latest updated version [27-29].

\section{IT Platform Including a Web-Based Call Center}

An IT platform was used by case managers to manage COPD patients' health records. This platform was connected to a call center that was accessible to PCPs and patients to allow them to contact the case manager. This was part of an intervention aimed at improving health or clinical related outcomes [22] and preventing or reducing of hospitalization [21].

\section{Electronic Communication Applications}

IT applications were used to provide (one-way) electronic communication using text, for example, fax and electronic messaging. This information was provided by specialty care professionals to inform primary care physicians about their patients.
Fax was used to inform GPs about chemotherapy and patient specifics [32]. To improve community pharmacists' control over medication-related problems related to $\mathrm{CKD}$, the predialysis clinic provided them with medication and clinical information by fax $[23,24]$. Case managers, specially trained nurses, aimed to improve the coordination and continuity of care for patients with colorectal cancer. They used electronic messaging to inform GPs about their patients, including contact information [33].

\section{Outcome Measures and Effects}

The most striking proximal (professional or provider) [23,32,33], intermediate (process) $[21,23,30,31,33]$, and distal (health or clinical and financial) [22-26,31] results are described for each IT category, and a comprehensive overview is presented in Multimedia Appendix 3.

\section{Electronic Decision Support}

A decision support tool described in an RCT was used with the aim to improve metabolic and cardiovascular risk factor control, process of care, and costs for diabetes patients [31]. In a pre-post feasibility study, electronic decision support was used to support care managers in their care of patients with CVD or heart failure [26].

\section{Health or Clinical and Financial Outcomes}

Electronic decision support for case management in a pre-post feasibility study showed multiple statistically significant outcomes, for example, days of physical activity per week increased from 2.5 to 4.2 days $(P<.01)$ and time from 19.9 to 32.9 min each time, self-monitoring increased by $20-27 \%$. Body mass index (BMI), low-density lipoprotein (LDL), systolic blood pressure (BP), and total cholesterol decreased by $10-20 \%$. Additionally, survey results indicate high levels of satisfaction among physicians, care managers, and patients [26]. However, Smith et al [31] found a significant difference between intervention and usual care for smoking cessation $(96.0 \%$, $343 / 358$ in the intervention; $93.0 \%, 257 / 277$ in the control group; $P=.04)$ and aspirin use $(66.0 \%, 238 / 358$ in the intervention; $52.0 \%, 145 / 277$ in the control group; $P=.001$ ). A significant effect on metabolic outcomes was not detected. Lower costs were reported benefiting the intervention group. The total mean costs of the intervention were US $\$ 6252$ compared with US $\$ 8564$ for the control group $(P=.02)$; the outpatient costs for the intervention were US $\$ 1842$ and US $\$ 2129$ for the control group $(P=.04)$. However, these costs were not specifically related to diabetes care [31].

\section{Electronic Health Records}

EHRs were used to (1) share (real-time) data by connecting primary and secondary EHRs [25,30], and (2) synchronize records by collecting professionals' input and storing patients data [27-29].

\section{Provider or Professional Outcomes}

Use of an EHR for hypertension patients was compared with specialists' outpatient- and nurse practitioner (NP) follow-up. Sixty-one percent $(90 / 147)$ of the GPs had a preference to continue shared care and 32\% (47/147) preferred shared care over the usual, outpatient- or NP care [28]. 


\section{Process Outcomes}

EHRs were used to inform GPs about hospital discharges. This had no significant effect on the number of PCP visits after discharge nor on rehospitalization rates $(18.77 \%, 351 / 1870)$ compared with the control group $(19.88 \%, 356 / 1791)$ [30]. The use of "synchronized" EHRs did not seem to affect the number of consultations [27], admissions [27,29], or GP consultations [29] compared with usual care. However, significant effects were noted for the number of patients receiving a complete (medical) review after 2 years $(82.4 \%, 220 / 267)$ in comparison with outpatients $(54.1 \%, 146 / 270)$ and with nurse practitioner (74.8\%, 202/270) follow-ups [28].

\section{Health or Clinical and Financial Outcomes}

Clinical information about diabetes patients was shared between GPs and hospital professionals. This had a significant positive effect on various clinical outcomes-for example, glycated hemoglobin (HbA1c), BMI, LDL, and cholesterol [25]. However, the use of "synchronized" health records showed no difference with usual care for most patient-related outcomes, such as metabolic control, psychosocial problems [27], or sleep disturbance [29].

\section{IT platform and Web-Based Call Center}

COPD patients' care managers were accessible for PCPs and patients via a call center that was an integral part of an IT platform in which care managers could also manage health records $[21,22]$.

\section{Health or Clinical and Financial Outcomes}

A significant effect on the number of patients without readmissions was detected: $55 \%(36 / 65)$ of patients in the intervention group compared with $33 \%$ (30/90) of patients in the control $(P=.03)[21]$.

The intervention was also evaluated on a range of clinical, health-related, quality of life and lifestyle aspects; and on self-management medical treatment and patients' satisfaction. Only statistically significant improvements in dyspnea and BMI were detected. Patients in the intervention had better knowledge of the name of their disease $(81 \%, 17 / 21$ vs $44 \%, 18 / 41$ in usual care group; $P=.005)$, awareness of identification of COPD exacerbations $(81 \%, 17 / 21$ vs $22 \%, 9 / 41$ in usual care group; $P<.001)$, and of exacerbations in early COPD treatment (90\%, $19 / 21$ vs $66 \%, 27 / 41$ in usual care group $P=.04$ ) than patients receiving usual care-without support from a case manager [22].

\section{Electronic Communication Applications}

Information was transferred from secondary to primary care using electronic communication applications, for example, fax [23,24,32,33].

\section{Provider or Professional Outcomes}

Overall, PCPs were satisfied about the interventions and information [23,32,33]. For example, GPs receiving extra information about their chemotherapy patients were more confident ( $7 \%$ difference with usual care, $P=.03$ ) and more satisfied than GPs receiving only the usual correspondence (10\% difference with usual care, $P=.002$ ) [32]. Jefford et al [32] found no effect for GP knowledge, whereas Lalonde et al [23] found that the knowledge of pharmacist in the intervention group increased by more than $30 \%$.

\section{Process Outcomes}

The majority of process-related outcomes improved significantly in the included interventions. For example, training combined with a communication network for pharmacists had positive effects on the number of pharmaceutical recommendations $[23,24]$. GPs were informed by electronic messaging in a care management intervention for patients with colorectal cancer. In the 9 months follow-up period, the case manager intervention showed a decrease in GPs contacting the hospital $(P=.008)$, and fewer patients contacted GPs during out-of-hours service (that is not daytime) $(P=.02)$ compared with the control group [33].

\section{Health or Clinical and Financial Outcomes}

An effect on systolic BP, but not on diastolic or BP control, was reported in one study [24].

\section{Risk of Bias}

An overview of the risk of bias is provided in Multimedia Appendix 4. No study was free from the risk of bias. Inherent to the type of intervention blinding either the participants or professionals was not possible. Of the 11 included (cluster) RCTs, 6 studies had adequate random sequence generation; in most cases, computer-generated systems were used. More than half of the studies had a low risk of bias for allocation assessment, mainly because of the use of numbered sealed envelopes. Other aspects that were rated for risk of bias were (1) selective reporting, (2) blinding of outcome assessment, and (3) incomplete outcome data. These items were often not reported, and therefore, score as an unclear risk of bias according to the Cochrane handbook [19].

\section{Discussion}

\section{Summary of Evidence}

We have systematically reviewed 13 studies focusing on IT-supported shared care for patients with a chronic disease. Overall, there seems to be much merit in IT supported shared care interventions.

The reviewed interventions were supported by four main categories of IT applications: (1) electronic decision support systems, (2) electronic platform and call center, (3) EHR, and (4) electronic communication applications. The main findings of these studies are (1) electronic decision support-based interventions showed a significant positive effect on reducing costs; (2) connected EHRs resulted in more PCP visits, less rehospitalization and better clinical outcomes; and (3) the use of an IT platform resulted in fewer readmissions and positive effects on some health or clinical outcomes. However, it failed to show positive effects on quality of life or doctor visits. Additionally, (4) the use of electronic communication applications showed positive results in terms of PCPs' satisfaction, confidence [32], and the lower number of GPs contacting the hospital [33]. However, effects on GPs' knowledge were inconsistent [23,32]. 
As IT often was only a small part of the intervention, it is hard to determine its real added value in shared care. The reviewed studies varied considerably with regard to the type of intervention, the studied patient population, the IT applications used, and the various outcome measures. As a result of this great variation, and because no study was free from the risk of bias, it is difficult to reliably compare the effects found between the various studies or to make valid generalizations about outcomes that hold true for most chronic patients.

The level of advancedness of included IT applications varied and they have evolved over time. The intervention studies conducted in 1994 [27-29] all used an EHR to manage clinical information and shared this (nonelectronically) between professionals. EHRs have evolved into connected systems that ensure real-time information exchange. Examples are the EHRs used in the studies of Gurwitz et al [30] and Carallo et al [25]. Surprisingly, in 2008 and 2011, fax was still used to transfer information from secondary to primary care, and on the other hand innovative electronic decision support systems were used as well [26,31]). Such "intelligent" systems support professionals in their care of patients, for example, by sending automatic alerts or providing tailored advice. Based on this review we regard this as the most advanced IT application to support shared care.

\section{Comparison With Previous Work}

The findings of our review are comparable with previous reviews on shared or integrated care, in the way that these also reported mixed overall results. For example, Smith et al reviewed the effectiveness of shared care studies for patients with chronic disease $[7,18]$. The results of the included studies were mixed, and therefore, they pose that it was not possible to draw conclusions about the effectiveness of the interventions. Also the reviewed interventions were complex and consisted of multiple elements that precluded attribution of the effects to the different elements. Additionally, in line with our review, the studies were of low methodological quality $[7,18]$.

Ouwens et al [34] reviewed integrated care interventions and also found heterogeneity in patient populations, outcomes, and interventions. Although integrated care appears to be an effective approach, this heterogeneity may lead to incorrect conclusions [34]. A similar conclusion was drawn in the review of Aubin et al on the effects of interventions to improve continuity of follow-up care for cancer patients. In this review, a shared care model was used in 14 of 63 studies, and even though some effects in separate studies were found, no clear conclusions could be drawn because the results were too mixed [35]. Again, just as in the review of Smith et al [7,18], the interventions were complex, which makes it hard to determine which elements of the intervention were effective and which were not. Overall, it seems difficult to determine the real added value of shared care as a result of mixed results and heterogeneity in the included populations and intervention elements.

The use of IT based interventions in these previous reviews was minimal and also a description of the applications and their effects was lacking $[7,18]$. We found several IT-supported share care interventions but unfortunately, we were unable to draw firm conclusions about the added value of IT because it is not evaluated as a single component.

\section{Future Research}

Nowadays, many IT applications have been or are being developed to support health care processes [16], but despite this, we only found a surprising small number of publications analyzing their effectiveness in a controlled study. The rapid development of IT applications for shared care purposes is currently not underpinned by rigorous studies showing its added value. Although in evidence-based medicine the RCT is regarded as the gold standard design, there may be drawbacks in using this design for evaluating health care IT applications. RCTs are, by nature, time and cost intensive and may not be able to keep up with fast developing technologies. In other words, when the results of a RCT are finally available, the IT may be outdated. Other research designs could provide more information and save time [36] and may better keep up with the rapid development of IT. Another approach to reflect the rapid development of IT is to measure the feasibility of an IT intervention in a smaller population within a larger RCT [37].

The assessment of the risk of bias of the studies indicates that there is room for improvement in several areas. For example, concealment of intervention allocation and the lack of blinding of participants were not clearly described. This can mean that the effects are overestimated, and it may also be due to the type of intervention. In future research, researchers should provide estimates (as blinding is seldom possible) about how likely it is that this will influence the outcomes. The measurements should also be described more accurately and preferably distinguish proximal or intermediate or distal outcomes because the exact mechanism of intervention and effects is often unclear. Also better standardization on outcome assessments by using a framework, such as the chronic care model (CCM) may be useful. This is a framework to improve clinical and functional outcomes for patients suffering from a chronic disease, and IT can support that model. Key elements are clinical information systems, including databases and care protocol systems. But other applications are also increasingly used to share data with patients, such as patient portals and PHRs. These are applications to provide patients with their clinical information and the ability to share this information [38,39]. Patients' needs are important, and care should be focused on patients' preferences to improve quality of care [40]. Professionals should work together, by means of a shared care model, to meet the needs of patients [41]. In line with this, the definition of shared care may be open to discussion or other care models may be increasingly relevant.

Future research must adapt to these aspects and developments. It is also relevant to examine the processes and time points for which IT will be most valuable in supporting shared care.

\section{Limitations}

A limitation of this study is the inclusion of "IT" as a search term in the initial search (title or abstract selection). We therefore might have missed studies that were supported by IT but did not mention this in the title or abstract. Furthermore, although we included a broad range of terms in our search, we 
may not have retrieved all studies that in fact are a shared care intervention. Our search was conducted from 2006 to January 2015, and we added IT-supported shared care studies from before 2006 from the review of Smith et al [7,18] Although unlikely, we might miss relevant studies from before 2006 that were not reviewed by Smith et al $[7,18]$ because they used slightly different search terms.

\section{Conclusions}

Despite the potential benefits of using IT to support shared care in chronic diseases, we found surprisingly few-whether controlled or uncontrolled-studies that substantiated these anticipated benefits. Studies showed a large heterogeneity in the study populations, outcome measures, and IT applications. The reviewed interventions reported many positive effects on (proximal) provider or professionals outcomes (such as GPs' satisfaction and confidence). To a lesser extent, positive effects on intermediate (GPs contacting the hospital) and distal outcomes (costs and readmissions) were also reported. Nonetheless, a firm conclusion cannot be drawn on the effect of IT-supported shared care - especially its clinical effect. As IT applications for shared care are developed and implemented rapidly, we are in need of more and better evidence on the specific added value of IT in shared care interventions, and this is expected to require innovative research methods.

\section{Acknowledgments}

This research was sponsored by charities.

\section{Conflicts of Interest}

None declared.

\section{Multimedia Appendix 1}

Search strategy in PubMed.

[PDF File (Adobe PDF File), 31KB-Multimedia Appendix 1]

\section{Multimedia Appendix 2}

Study and information technology (IT) characteristics.

[PDF File (Adobe PDF File), 287KB-Multimedia Appendix 2]

\section{Multimedia Appendix 3}

Outcome measures and effects; + indicates a positive effect and indicates a negative effect.

[PDF File (Adobe PDF File), 170KB-Multimedia Appendix 3]

\section{Multimedia Appendix 4}

Risk of bias.

[PDF File (Adobe PDF File), 17KB-Multimedia Appendix 4]

\section{References}

1. World Health Organization, Regional office for Europe Diabetes. WHO. Data and statistics URL: http://www.euro.who.int/ en/health-topics/noncommunicable-diseases/diabetes [accessed 2016-01-22] [WebCite Cache ID 6nhwKHM80]

2. European COPD Coalition. Key facts URL: http://www.copdcoalition.eu/about-copd/key-facts [accessed 2016-01-22] [WebCite Cache ID 6nhwRRbpz]

3. Hewitt M, Greenfield S, Stovall E. From cancer patient to cancer survivor: lost in transition. Washington, DC: National Academies; 2006.

4. Corrigan JM. NAP. 2005. Crossing the quality chasm URL: https://www.nap.edu/login.php?record id=11378 [accessed 2017-01-22] [WebCite Cache ID 6nhx4kPIV]

5. Wagner EH, Austin BT, Davis C, Hindmarsh M, Schaefer J, Bonomi A. Improving chronic illness care: translating evidence into action. Health Aff (Millwood) 2001;20(6):64-78 [FREE Full text] [Medline: 11816692]

6. Hickman M, Drummond N, Grimshaw J. A taxonomy of shared care for chronic disease. J Public Health Med 1994 Dec;16(4):447-454. [Medline: 7880576]

7. Smith SM, Allwright S, O'Dowd T. Does sharing care across the primary-specialty interface improve outcomes in chronic disease? a systematic review. Am J Manag Care 2008 Apr;14(4):213-224 [FREE Full text] [Medline: 18402514] 
8. Branger PJ, van der Wouden JC, Schudel BR, Verboog E, Duisterhout JS, van der Lei J, et al. Electronic communication between providers of primary and secondary care. BMJ 1992 Oct 31;305(6861):1068-1070 [FREE Full text] [Medline: 1467688]

9. van Walraven C, Taljaard M, Bell CM, Etchells E, Zarnke KB, Stiell IG, et al. Information exchange among physicians caring for the same patient in the community. CMAJ 2008 Nov 04;179(10):1013-1018 [FREE Full text] [doi:

10.1503/cmaj.080430] [Medline: 18981442]

10. Kripalani S, LeFevre F, Phillips CO, Williams MV, Basaviah P, Baker DW. Deficits in communication and information transfer between hospital-based and primary care physicians: implications for patient safety and continuity of care. JAMA 2007 Feb 28;297(8):831-841. [doi: 10.1001/jama.297.8.831] [Medline: 17327525]

11. Cruz-Correia RJ, Vieira-Marques PM, Ferreira AM, Almeida FC, Wyatt JC, Costa-Pereira AM. Reviewing the integration of patient data: how systems are evolving in practice to meet patient needs. BMC Med Inform Decis Mak 2007 Jun 12;7:14 [FREE Full text] [doi: 10.1186/1472-6947-7-14] [Medline: 17565667]

12. Graetz I, Reed M, Shortell SM, Rundall TG, Bellows J, Hsu J. The next step towards making use meaningful: electronic information exchange and care coordination across clinicians and delivery sites. Med Care 2014 Dec;52(12):1037-1041 [FREE Full text] [doi: 10.1097/MLR.0000000000000245] [Medline: 25304020]

13. García GM, Valenzuela MM, Martínez OJ, Otero LM, Ponz CE, López AT, et al. Results of a coordination and shared clinical information programme between primary care and nephrology. Nefrologia 2011;31(1):84-90 [FREE Full text] [doi: 10.3265/Nefrologia.pre2010.Oct.10615] [Medline: 21270918]

14. Bates DW, Gawande AA. Improving safety with information technology. N Engl J Med 2003 Jun 19;348(25):2526-2534. [doi: 10.1056/NEJMsa020847] [Medline: 12815139]

15. Shekelle PG, Morton SC, Keeler EB. Costs and benefits of health information technology. Evid Rep Technol Assess (Full Rep) 2006 Apr(132):1-71. [Medline: 17627328]

16. Chaudhry B, Wang J, Wu S, Maglione M, Mojica W, Roth E, et al. Systematic review: impact of health information technology on quality, efficiency, and costs of medical care. Ann Intern Med 2006 May 16;144(10):742-752. [Medline: 16702590]

17. Bodenheimer T. Coordinating care-a perilous journey through the health care system. N Engl J Med 2008 Mar 6;358(10):1064-1071. [doi: 10.1056/NEJMhpr0706165] [Medline: 18322289 ]

18. Smith SM, Allwright S, O'Dowd T. Effectiveness of shared care across the interface between primary and specialty care in chronic disease management. Cochrane Database Syst Rev 2007 Jul 18(3):CD004910. [doi: 10.1002/14651858.CD004910.pub2] [Medline: 17636778]

19. Higgins JP, Green S. Cochrane. Cochrane handbook for systematic reviews of interventions URL: http://handbook. cochrane.org/part 2 general methods for cochrane reviews.htm [accessed 2016-01-22] [WebCite Cache ID 6nhxPJqth]

20. Liberati A, Altman DG, Tetzlaff J, Mulrow C, Gøtzsche PC, Ioannidis JP, et al. The PRISMA statement for reporting systematic reviews and meta-analyses of studies that evaluate health care interventions: explanation and elaboration. J Clin Epidemiol 2009 Oct;62(10):e1-34 [FREE Full text] [doi: 10.1016/j.jclinepi.2009.06.006] [Medline: 19631507]

21. Casas A, Troosters T, Garcia-Aymerich J, Roca J, Hernández C, Alonso A, Members of the CHRONIC Project. Integrated care prevents hospitalisations for exacerbations in COPD patients. Eur Respir J 2006 Jul;28(1):123-130 [FREE Full text] [doi: $\underline{10.1183 / 09031936.06 .00063205]}$ [Medline: 16611656]

22. Garcia-Aymerich J, Hernandez C, Alonso A, Casas A, Rodriguez-Roisin R, Anto JM, et al. Effects of an integrated care intervention on risk factors of COPD readmission. Respir Med 2007 Jul;101(7):1462-1469 [FREE Full text] [doi: 10.1016/j.rmed.2007.01.012] [Medline: 17339106]

23. Lalonde L, Normandeau M, Lamarre D, Lord A, Berbiche D, Corneille L, et al. Evaluation of a training and communication-network nephrology program for community pharmacists. Pharm World Sci 2008 Dec;30(6):924-933. [doi: 10.1007/s11096-008-9253-0] [Medline: 18802782]

24. Santschi V, Lord A, Berbiche D, Lamarre D, Corneille L, Prud'homme L. Impact of collaborative and multidisciplinary care on management of hypertension in chronic kidney disease outpatients. J Pharm Health Serv Res 2011 Mar 22;2(2):79-87. [doi: 10.1111/j.1759-8893.2011.00038.x]

25. Carallo C, Scavelli FB, Cipolla M, Merante V, Medaglia V, Irace C, et al. Management of type 2 diabetes mellitus through telemedicine. PLoS One 2015;10(5):e0126858 [FREE Full text] [doi: 10.1371/journal.pone.0126858] [Medline: 25974092]

26. Ciccone MM, Aquilino A, Cortese F, Scicchitano P, Sassara M, Mola E, et al. Feasibility and effectiveness of a disease and care management model in the primary health care system for patients with heart failure and diabetes (Project Leonardo). Vasc Health Risk Manag 2010 May 06;6:297-305 [FREE Full text] [Medline: 20479952]

27. DICE. Integrated care for diabetes: clinical, psychosocial, and economic evaluation. Diabetes integrated care evaluation team. BMJ 1994 May 07;308(6938):1208-1212 [FREE Full text] [Medline: $\underline{\text { 8180540] }}$

28. McGhee SM, McInnes GT, Hedley AJ, Murray TS, Reid JL. Coordinating and standardizing long-term care: evaluation of the west of Scotland shared-care scheme for hypertension. Br J Gen Pract 1994 Oct;44(387):441-445 [FREE Full text] [Medline: $\underline{7748631]}$ 
29. Drummond N, Abdalla M, Buckingham J, Beattie J, Lindsay T, Osman L, et al. Integrated care for asthma: a clinical, social, and economic evaluation. Grampian asthma study of integrated care (GRASSIC). BMJ 1994 Feb 26;308(6928):559-564 [FREE Full text] [Medline: $\underline{8148678]}$

30. Gurwitz JH, Field TS, Ogarek J, Tjia J, Cutrona SL, Harrold LR, et al. An electronic health record-based intervention to increase follow-up office visits and decrease rehospitalization in older adults. J Am Geriatr Soc 2014 May;62(5):865-871 [FREE Full text] [doi: 10.1111/jgs.12798] [Medline: 24779524]

31. Smith SA, Shah ND, Bryant SC, Christianson TJ, Bjornsen SS, Giesler PD, et al. Chronic care model and shared care in diabetes: randomized trial of an electronic decision support system. Mayo Clin Proc 2008 Jul;83(7):747-757. [doi: $\underline{10.4065 / 83.7 .747]}$ [Medline: 18613991$]$

32. Jefford M, Baravelli C, Dudgeon P, Dabscheck A, Evans M, Moloney M, et al. Tailored chemotherapy information faxed to general practitioners improves confidence in managing adverse effects and satisfaction with shared care: results from a randomized controlled trial. J Clin Oncol 2008 May 10;26(14):2272-2277. [doi: 10.1200/JCO.2007.14.7710] [Medline: 18467717]

33. Wulff CN, Vedsted P, Søndergaard J. A randomized controlled trial of hospital-based case management in cancer care: a general practitioner perspective. Fam Pract 2013 Feb;30(1):5-13. [doi: 10.1093/fampra/cms050] [Medline: 22952209]

34. Ouwens M, Wollersheim H, Hermens R, Hulscher M, Grol R. Integrated care programmes for chronically ill patients: a review of systematic reviews. Int J Qual Health Care 2005 Apr;17(2):141-146. [doi: 10.1093/intqhc/mzi016] [Medline: 15665066]

35. Aubin M, Giguère A, Martin M, Verreault R, Fitch MI, Kazanjian A, et al. Interventions to improve continuity of care in the follow-up of patients with cancer. Cochrane Database Syst Rev 2012 Jul 11(7):CD007672. [doi: 10.1002/14651858.CD007672.pub2] [Medline: 22786508]

36. Baker TB, Gustafson DH, Shah D. How can research keep up with eHealth? ten strategies for increasing the timeliness and usefulness of eHealth research. J Med Internet Res 2014;16(2):e36 [FREE Full text] [doi: 10.2196/jmir.2925] [Medline: 24554442]

37. Kuijpers W, Groen WG, Oldenburg HS, Wouters MW, Aaronson NK, van Harten Wim H. Development of MijnAVL, an interactive portal to empower breast and lung cancer survivors: an iterative, multi-stakeholder approach. JMIR Res Protoc 2015;4(1):e14 [FREE Full text] [doi: 10.2196/resprot.3796] [Medline: 25614924]

38. Kahn JS, Aulakh V, Bosworth A. What it takes: characteristics of the ideal personal health record. Health Aff (Millwood) 2009;28(2):369-376 [FREE Full text] [doi: 10.1377/hlthaff.28.2.369] [Medline: 19275992]

39. Goldzweig CL, Orshansky G, Paige NM, Towfigh AA, Haggstrom DA, Miake-Lye I, et al. Electronic patient portals: evidence on health outcomes, satisfaction, efficiency, and attitudes: a systematic review. Ann Intern Med 2013 Nov 19;159(10):677-687. [doi: 10.7326/0003-4819-159-10-201311190-00006] [Medline: 24247673]

40. Institute of Medicine, National Academy of Engineering. In: Reid PP, Grossman JH, Fanjiang G, editors. Building a Better Delivery System: A New Engineering/Health Care Partnership. Washington, DC: National Academies Press; 2005.

41. Bazzell JL, Spurlock A, McBride M. Matching the unmet needs of cancer survivors to resources using a shared care model. J Cancer Educ 2015 Jun;30(2):312-318. [doi: 10.1007/s13187-014-0708-9] [Medline: 25103849]

\author{
Abbreviations \\ BMI: body mass index \\ BP: blood pressure \\ CKD: chronic kidney disease \\ COPD: chronic obstructive pulmonary disease \\ CVD: cardiovascular disease \\ EHR: electronic health record \\ GP: general practitioner \\ IT: information technology \\ LDL: low-density lipoprotein \\ NP: nurse practitioner \\ PCP: primary care physician \\ PHR: personal health record \\ RCT: randomized controlled trial
}


Edited by G Eysenbach; submitted 25.01.17; peer-reviewed by P Gee, J Apolinário-Hagen; comments to author 26.03.17; revised version received 10.04.17; accepted 24.04.17; published 22.06.17

Please cite as:

Kooij L, Groen WG, van Harten WH

The Effectiveness of Information Technology-Supported Shared Care for Patients With Chronic Disease: A Systematic Review

J Med Internet Res 2017;19(6):e221

URL: http://www.jmir.org/2017/6/e221/

doi: $10.2196 /$ jmir.7405

PMID: 28642218

CLaura Kooij, Wim G Groen, Wim H van Harten. Originally published in the Journal of Medical Internet Research (http://www.jmir.org), 22.06.2017. This is an open-access article distributed under the terms of the Creative Commons Attribution License (https://creativecommons.org/licenses/by/4.0/), which permits unrestricted use, distribution, and reproduction in any medium, provided the original work, first published in the Journal of Medical Internet Research, is properly cited. The complete bibliographic information, a link to the original publication on http://www.jmir.org/, as well as this copyright and license information must be included. 